\title{
Angiopoietin-1 for Myocardial Angiogenesis
}

\author{
Vien Khach Lai, Muhammad Zeeshan Afzal, \\ Muhammad Ashraf and Khawaja Husnain Haider \\ Department of Pathology \\ University of Cincinnati, Cincinnati, $\mathrm{OH}$, \\ USA
}

\section{Introduction}

In response to ischemic damage, the heart undergoes vicious process of remodeling wherein the damaged myocardium is replaced by scar tissue and as compensatory mechanism, its existing collateral vessels and neovascularization with concomitant changes in cell recruitment, multiplication and cytokine/growth factor action. Angiogenesis is a complex process which involves an interplay between multiple pro- and anti-angiogenic factors and a harmonized interaction between endothelial progenitor cells, smooth muscle cells, pericytes and supportive environment. Besides Vegf/ Vegf receptor system, angiopoietin family of pro-angiogenic growth factors in conjunction with their receptor system are critical for vascular protection, remodeling, proliferation and maturation beside preservation of the integrity of newly formed vascular structures for functional activity (Thurston et al. 2000; Saharinen et al. 2005; Brindle, Saharinen et al. 2006).

An outside intervention to support the inefficient intrinsic myocardial repair processes by administration of stem/ progenitor cells has emerged as a promising strategy for the treatment of ischemic heart diseases. The transplanted stem cells have shown both myogenic as well as vasculogenic differentiation potential and participate in the myocardial regeneration via angiomyogenesis (Chen et al. 2010; Uemura et al. 2006; Eguchi et al. 2007). In addition to differentiation, stem cells can also ameliorate inflammation, migrate to ischemic regions and secrete bioactive molecules as a part of their paracrine activity and significantly contribute myocardial protection and angiogenesis. Alternatively, multimodal therapeutic strategies have also been adopted to accentuate the angiomyogenic potential of stem cells. This includes preconditioning of stem cells with growth factor treatment, their genetic modification with plasmids encoding for various angiogenic growth factors and concomitant administration of recombinant angiogenic growth factor proteins (Jiang et al. 2006; Haider et al. 2008; Kim et al. 2009; Lu et al. 2009). Such multimodal treatment strategies have elicited beneficial effects in terms of improving stem cell survival and enhancing their paracrine behavior besides stimulation of angiogenesis through direct recruitment, proliferation and maturation of precursor cells such as endothelial progenitor cells, mesenchymal stem cells and monocytes to the ischemic heart (Banai et al. 1994; Hiasa et al. 2004; Elmadbouh et al. 2007; Haider et al. 2008). We discuss here the biological regulation of angiopoietin-1 expression, its interaction with specific receptor system and the advantages of transgenic over expression of angiopoietin-1 either alone or in combination 
with Vegf to support angiogenesis as a therapeutic option for the treatment of ischemic heart disease.

\section{Angiopoietin-1}

\subsection{Angiopoietin-1 and Tie2 ligand/receptor interaction in angiogenesis}

The angiopoietin family of proteins consists of four members, all of which interact with the endothelial receptor tyrosine kinase, (tunica intima endothelial kinase 2, Tie2) (Thomas \& Augustin 2009). Whereas two of these factors, angiopoietin- 1 and angiopoietin-4, are constitutive agonists and Tie2 receptor activators (Davis et al. 1996), angiopoietin-2 and angiopoietin-3 have different effector functions and may activate or antagonize angiopoietin-1 induced Tie2 phosphorylation (Suri et al. 1996; Valenzuela et al. 1999; Fiedler et al. 2003). The essential role of angiopoietin-1 in the expansion and stabilization of newly formed vessels has been widely demonstrated (Suri et al. 1998). The process of vasculogenesis consists of differentiation, proliferation, and coalescence of vascular endothelial cells to establish a primitive vascular network in the early stage. This is followed by maturation of the neovasculature through the process of angiogenic remodeling that involves sprouting, branching, pruning, differential growth of vessels, and the recruitment of supporting cells (Suri et al. 1998; Hattori et al. 2001).

Both angiopoietin- 1 and angiopoietin- 2 have discrete participation in the occurrence of angiogenic cascade wherein angiopoietin-2 accumulates at the leading edge of proliferating vessels and angiopoietin-1 shows diffused localization behind the leading edge (Suri et al. 1998). Based on this distinct pattern of expression, it is suggested that angiopoietin-2 negatively mediates Tie2 activation and destabilizes the vessels to make these responsive to other angiogenic growth factors including Vegf, Pdgf and Fgf. On the contrary, angiopoietin-1 activates Tie2 and triggers remodeling and stabilization of the newly formed vasculature which leads to its maturation (Suri et al. 1998; Huang et al. 2009). The antagonizing activity of angiopoietin-2 is imperative for normal vascular maturation and spatial configuration (Feng et al. 2009). Over expression of angiopoietin-1 results in increased number, size and branches of the blood vessels without affecting the association among endothelial cells and with no evidence of plasma leakage, edema, or erythrocyte extravasation unlike Vegf (Suri et al. 1998; Thurston et al. 1999; Thurston et al. 2000; Kim et al. 2002). Angiopoietin-1 also contributes to attenuation of inflammatory response by mediating anti-permeability effects to counter Vegf and tumor necrosis factor (TNF)induced inflammatory molecules in the endothelial cells such as vascular adhesion molecule-1 (VCAM-1), intercellular adhesion molecule-1 (ICAM-1) and endothelin-1 which control cell-cell interaction, maintain vascular quiescence and prevent leakiness (Kim et al. 2002; Hughes et al. 2003; Jeon et al. 2003; McCarter et al. 2006).

Tie2 receptor, a member of receptor tyrosine kinase family, consists of an extracellular domain, a trans-membrane domain and a split intracellular kinase domain (Takahara et al. 2004). This receptor is more specifically expressed on vascular endothelium in both quiescence and active states although it is also found on some other cell types such as smooth muscle cells, fibroblasts, mural cells, ganglion cells and carcinoma cells (Dumont et al. 1992; Takahara et al. 2004; Kosacka et al. 2005; Nakayama et al. 2005; Hamaguchi et al. 2006). Tie2 is highly conserved from zebra fish to mammals with the greatest amino acid homology occurring in the kinase domain, indicating the importance of its biological function (Lyons et al. 1998). Disrupting the function of Tie2 in transgenic mice was lethal 
and resulted in early embryonic death due to failure of vascular branching and differentiation. Homozygous mutated embryos also displayed abnormalities in the development of the heart (Dumont et al. 1994; Sato et al. 1995). Lack of Tie2 also resulted in angiogenic defects in term of vessel branching and remodeling, and displayed defects in the developing vessels to have scarce peri-endothelial cells and thinner collagen-like fibers (Suri et al. 1996). Dysregulated expression of Tie2 have also been observed in several clinical diseases including venous malformations, intramuscular hemangiomas, pulmonary hypertension and infantile hemangiomas (Yu et al. 2001; Wang et al. 2004; Morris et al. 2005). On the contrary, overexpression of angiopoietin- 1 in the skin of experimental animal models led to the formation of highly branched and larger vessels, and resulted in reduction of microvascular leakage (Suri et al. 1998; Thurston et al. 1999). Tie2 over expression in the skin caused psoriasis-like phenotype after birth and persisted throughout adulthood, and was featured by epidermal hyperplasia, accumulation of inflammatory cells and altered dermal angiogenesis (Voskas et al. 2005). These findings clearly suggested that a delicate level of Tie2 receptor was required for physiological functioning and any unregulated induction or loss of Tie2 resulted in potentially worsened effects. Despite considerable similarity with Tie1, experiments with Tie1- or Tie2-deficient mice have provided evidence of their distinct functions in response to different members of angiopoietin family (Seegar et al. 2011).

\subsection{Angiopoietin-1, Tie2 receptor and intracellular signaling}

It is interesting to note that angiopoietin- 1 and angiopoietin-2 have different effects on vascular formation and development, however, they bind to Tie2 receptor with distinct kinetics of release following binding thus indicating that activation of Tie 2 receptor is regulated independently by these two molecules. In fact, angiopoietin-2, a natural antagonist of angiopoietin-1 (Maisonpierre et al. 1997), binds to Tie2 receptor without its activation (Davis et al. 2003). Similarly, structural characteristics and distinguishable interaction with other molecules in the extracellular environment of the ligands may also essentially contribute to their counteractive properties (Kim et al. 2005). More recent studies have shown that the effects of angiopoietin- 1 and angiopoietin- 2 on the receptor tyrosine kinase Tie2 are differentially regulated at the endothelial cell surface (Hansen et al. 2010) and a critical balance is maintained between angiopoietin- 1 and angiopoietin- 2 expression by sonic hedgehog and fibroblast growth factor-2 during angiogenesis (Fujii \& Kuwano, 2010). Phosphorylation of tyrosine residues of Tie2 occurs subsequent to binding with angiopoietin-1 and activates kinase domain of the receptor to initiate various downstream intracellular signaling cascades (Murray et al. 2001). The phosphorylation of tyrosine residues on the intracellular domain of Tie2 receptor interacts with the p85 subunit of PI3K via Src homology 2 or phosphotyrosine binding domain. These molecular changes result in activation of PI3K and its downstream Akt in the endothelial cells and ultimately lead to multiple responses such as cell survival, differentiation and chemotaxis (Witzenbichler et al. 1998; Fujikawa et al. 1999; Abdel-Malak et al. 2009; Bai et al. 2009). Although some studies have already demonstrated that angiopoietin-1 mediated activation of Tie 2 does not cause mitogenesis of endothelial cells, the others have reported a pro-proliferative effect of angiopoietin-1 on vascular cells (Kanda et al. 2005; Abdel-Malak et al. 2009). These contradictions in the data may be explained on the basis of the observation that angiopoietin-1 may induce various effects on endothelial cells depending on the tissue type and conditional environments. 
Angiopoietin-1 activity also involves Forkhead box O-1 (FOXO1) transcription factor which principally acts as a regulator of cell cycle and endothelial cell functions in vascular destabilization and remodeling (Kanda et al. 2005; Evans-Anderson et al. 2008). Angiopoietin-1 is known to inhibit the activity of FOXO1 via phosphorylation and promotes cell proliferation in the cultured endothelial cells by upregulation of cyclin D1 downstream of FOXO1 (Kanda et al. 2005; Huang \& Tindall 2007). Phosphorylation of FOXO1 by Akt in the endothelial cells occurs at three conserved sites which results in the inhibition of FOXO1 by promoting its translocation from the nucleus to the cytoplasm (Daly et al. 2004; Huang \& Tindall 2007). In addition to interaction with FOXO1, GATA3 which is highly expressed in human endothelial cells especially in the large vessels, plays a significant role in the expression of angiogenesis related genes and endothelial cell functions subsequent to stimulation with angiopoietin-1 (Song et al. 2009). Knock down of GATA3 significantly abrogated these effects of angiopoietin-1. Besides these transcription factors, angiopoietin-1 can activate MAPK in the cultured endothelial cells (Fujikawa et al. 1999; Kim et al. 2002; Zhu et al. 2002). Pharmacological inhibition of ERK1/2 abolishes Tie2 phosphorylation and its downstream signaling for morphogenesis of capillary endothelium and suppresses endothelial cell proliferation which are involved in angiogenesis (Kim et al. 2002). However, inhibition of ERK1/2 activity in endothelial cells does not effect angiopoietin-1-induced survival and migration (Fujikawa et al. 1999). Hence, it is suggested that MAPK activity as a consequence of Tie2 activation during angiogenesis is more important for endothelial sprouting and branching than for endothelial recruitment and maintenance. On the other hand, angiopoietin-1 mediated activation of p38 MAPK signaling promoted mural cell recruitment during angiogenesis (Zhu et al. 2003). Angiopoietin-1 also has the ability to directly bind to the monocytes without interacting with Tie2 and promote their transendothelial migration by directly activating PI3K for its role in inflammatory angiogenesis (Ahmad et al. 2010).

\subsection{Angiopoietin-1, Tie2 receptor and extracellular response}

Under physiological conditions, endothelial cells of the vasculature remain quiescent in the inner layer of vessels. However, during active vascular remodeling in response to pathological conditions like vascular occlusion, myocardial infarction or de-novo vascular formation, circulating endothelial progenitors and local endothelial cells migrate to the ischemic areas. More so, some of these cells penetrate and traverse to distant sites of the occluded vessels to participate in the repair process. Angiopoietin-2, which is mainly released by endothelial cells and localized at the site of vascular remodeling, functions as a Tie2 blocker and promotes the destabilization of pericytes from existing vessels and increases vascular permeability. This in turn allows the infiltration of proteases, cytokines and angiogenic cells to support robust angiogenic response. The blood vessels are thus formed by the complex contribution of an intricate network of smooth muscle layer that surrounds endothelial cells in arteries, arterioles and veins resulting from migration, proliferation and interaction of different cell types like pericytes, smooth muscle cells and fibroblasts (Asahara et al. 1999; Carmeliet 2000; Bentley et al. 2009). It is suggested that interaction between angiopoietin- 1 and Tie2 also regulates cross-talk between endothelial cells and pericytes (Davis et al. 1996; Sundberg et al. 2002). Angiopoietin-1 is a pericyte derived signal that mediates maturation and quiescence of the microvascular endothelium (Armulik et al. 2005). In addition to its role as an effector for the secondary step of vascular formation, angiopoietin-1 can stimulate endothelial cell migration and induce angiogenesis 
independent of its interaction with angiopoietin-2 or Vegf (Koblizek et al. 1998; Hayes et al. 1999; Babaei et al. 2003). The pro-angiogenic activity of angiopoietin-1 independent of Vegf involves phosphorylation of Tie2 and activation of PI3K/Akt signaling. These observations have been substantiated by in-vivo experimental evidence which showed that the angiogenic efficacy of angiopoietin-1 alone was comparable to that of Vegf stimulation (Babaei et al. 2003). More recent studies have shown that angiopoietin- 1 also regulate the functions of hematopoietic stem cells in the bone marrow. Treatment of ckit+ cells with angiopoietin-1 helped the cells to maintain their functional activity in vitro on long term basis, however, with little influence on their colony forming potential (Gomei et al. 2010).

\subsection{Angiopoietin-1, Tie2 and anti-apoptotic effect}

Angiopoietin-1 is critical for cell survival and proliferation and functions via PI3K/Akt and MAPK/ERK signaling pathway (Daly et al. 2004; Kanda et al. 2005). ERK1/2 kinases have important role in regulation of apoptosis in various cells including endothelial cells wherein ERK1/2 have been consistently shown to mediate the anti-apoptotic effects of VEGF and angiopoietin- 1 by targeting caspase- $9,-3$ and -7 . Angiopoietin- 1 also induces p38 MAPK phosphorylation as a part of its anti-apoptotic activity in the endothelial cells (Gratton et al. 2001; Harfouche et al. 2003). The pro-survival effects of angiopoietin-1 have been extensively studied in variety of cells against pro-apoptotic stimuli (Tuo et al. 2010; Lee et al. 2008; Liu et al. 2008; Bai et al. 2009). In most cases, angiopoietin-1 treatment phosphorylated Tie2 receptors leading to activation of Akt signaling. Treatment of neuronal progenitor cells with angiopoietin-1 protected the cells against oxygen-glucose deprivation induced apoptosis by activation of PI3K/Akt to inhibit pro-apoptotic signaling (Bai et al. 2009). Similarly, activation of pro-apoptotic signaling was reversed in myocardial endothelial cells in high glucose culture conditions upon treatment with angiopoietin- 1 which incidentally also increased angiogenesis (Tuo et al. 2010). These salutary effects of angiopoietin-1 were however, antagonized and blunted by angiopoietin-2. Treatment with angiopoietin-1 protein or its transgenic expression in endothelial cells also induces some secondary mediators such as interleukin-8 through ERK1/2, SAPK/JNK, and PI3K pathways, which trigger c-Jun phosphorylation on Ser63 and Ser73 (Abdel-Malak et al. 2008). Interleukin-8 then acts in autocrine fashion to suppress apoptosis and facilitate cell proliferation and migration (Abdel-Malak et al. 2008).

\section{Angiopoietin-1 gene delivery in combination with Vegf}

Whereas Vegf is one of the most potent vasoactive growth factors which is involved in angiogenesis and regulates vascular permeability, angiopoietin- 1 is also being recognized for its angiogenic potential besides its role as a vascular stability factor. Both of these growth factors are discretely produced in a succession during the development of mature blood vessels (Thurston, 2002). Angiopoietin-1 acts as a mitogen for endothelial cells and synergistically induces sprout formation with Vegf (Koblizek et al. 1998). The regulatory mechanism of angiopoietin-1 induced neovascularization involves pro-survival effects on the endothelial cells by activation of PI3K/Akt signaling and stabilization of nascent blood vessels to become leak resistant (Thurston et al. 2000).

Both Vegf and angiopoietin-1 have been extensively used for angiogenic protein or gene therapy to exploit complementarities between their functional relationship (Zhu et al. 2002; Cheng et al. 2007). Given a coordinated role of angiopoietin-1 and Vegf during both 
physiologic and pathologic development of blood vessels, simultaneous use of the two growth factors have been reported for the treatment of tissue ischemia (Gale et al. 2002; Ye et al. 2007). The application of this combinatorial growth factor therapy approach is not only for induction of angiogenesis; it is also intended to involve circulating endothelial progenitor cells. These progenitors then home into the ischemic tissues in response to the concentration gradient for participation in the ongoing repair process of vasculogenesis (Kalka et al. 2000; Wang et al. 2006). We have already reported the feasibility of combining stem cell mobilization from bone marrow in combination with Vegf gene delivery to the infarcted heart to show that the mobilized stem cells homed into the heart and participated in myocardial angiogenesis (Wang et al. 2006). Although the use of recombinant growth factors has given encouraging results with both Vegf and angiopoietin-1, the very short biological half-life of these growth factors warrants alternative treatment strategies. A more recent study has reported covalent immobilization of Vegf and angiopoietin-1 onto threedimensional porous collagen scaffolds using 1-ethyl-3-[3-dimethylaminopropyl] carbodiimide hydrochloride (EDC) chemistry to enhance the duration of the growth factors availability and effectiveness (Chiu \& Radisic, 2011).

As an alternative to recombinant protein administration, transgenic expression of angiopoietin-1 and Vegf gene therapy is being assessed to achieve arteriogenesis and angiogenesis for the treatment of myocardial ischemia (Samuel et al. 2010; Siddiqui et al. 2003; Ye et al. 2007). The efficacy of Vegf and angiopoietin-1 gene delivery to the heart has been extensively studied to promote angiogenesis and improve regional blood flow et al. 2007; Haider, Ye et al. 2004). The authors reported the first bi-cistronic adenoviral vector encoding for Vegf and angiopoietin-1 for co-expression of the two angiogenic growth factors. The vector was used to genetically modify stem cells for overexpression of angiopoietin-1 and Vegf. Transplantation of genetically modified skeletal myoblasts demonstrated development of functionally mature blood vessels in the infarcted heart and in the hind limb ischemia model in rabbits (Niagara et al. 2004; Ye et al. 2007). These observations were in harmony with the previously published data suggesting enhanced perfusion accompanied by the development of stable and mature blood vessels with combined Vegf and angiopoietin-1 administration (Arsic et al. 2004; Gurunluoglu et al. 2002; Shyu et al. 2003). In a recently reported study, Tao et al. co-expressed Vegf/angiopoietin-1 using adeno-associated viral vectors (AAVs) expressing cardiac-specific and hypoxiainducible Vegf and Ang1 into the porcine infarcted heart immediately after ligation of the left descending coronary artery (Tao et al. 2010). Vegf and Ang1 were predominantly expressed in the heart in the infarct and border of the infarct. Gated single-photon emission computed tomography showed improved cardiac function and myocardial perfusion at 8 weeks after vector injection which corresponded well with higher vascular density. They also observed higher level activation of Akt and Bcl-xL, less Caspase-3 and Bad, and reduced TUNEL positivity in angiopoietin-1/ Vegf treated animal hearts. These results showed that simultaneous expression of angiopoietin-1/ Vegf in the infarcted heart stimulated pro-survival pathways besides improved regional blood flow. Although the authors claimed to have observed significant change in the number of cycling cardiomyocytes subsequent to angiopoietin-1/ Vegf overexpression, this may be insufficient to replace the massive loss of the functioning cardiomyocytes in the infarcted heart. Although direct injection of angiopoietin-1 and Vegf growth factors has been shown to significantly improve the regional blood flow in the ischemic heart, this strategy if combined with stem cell therapy would be more effective in addressing the core issue of myocardial regeneration which requires neomyogenesis for replacement of the scar tissue. 


\section{Combining stem cell transplantation and Angiopoietin-1 delivery}

Gene delivery strategy has developed over the years from direct plasmid injection to stem cell based ex-vivo delivery strategy. Stem cells are excellent carriers of therapeutic genes for delivery to the various body tissues and organs including the heart (Suzuki et al. 2001; Yau et al. 2007; Ye et al. 2007; Haider et al. 2008). Despite all the progress made, it remains to be defined whether cell based gene therapy can overcome several potential impediments such as poor transfection efficiency, unregulated transgene expression, low survival rate of transplanted cells into ischemic zones etc. On the same note, there are a number of parameters which require optimization including cell type, number of transfected cells to be transplanted, time of cell transplantation after infarction, and route of cell transplantation.

Angiopoietin- 1 is one of the many angiogenic growth factors which have been extensively studied for pro-angiogenic activity in the ischemic tissues. We performed a comparative assessment of the methods to deliver angiopoietin-1 gene delivery for angiogenic repair of the infarcted heart using an experimental porcine heart model of chronic infarction (Ye et al. 2007). Our results showed that skeletal myoblast based delivery of angiopoietin- 1 transgene was more effective as compared to the approach of direct injection of adenoviral vector encoding for angiopoietin-1. The genetically modified skeletal myoblasts carrying angiopoietin-1 transgene served as a reservoir of the transgene product and ensured localized release of angiopoietin-1 at the site of the cell graft without safety concerns associated with the use of direct injection of adenoviral vector (Ye et al. 2007). Besides we observed extensive survival of the transplanted skeletal myoblasts which underwent myogenic differentiation to repopulate the infarcted myocardium.

Given that the development of stable and functional blood vessels is regulated by a critical balance between several pro- and anti-angiogenic factors which also co-ordinate with various vasculogenic cells, we hypothesized that a single angiogenic factor may be insufficient to achieve the desired outcome. We therefore opted to combine angiopoietin-1 and Vegf for co-expression to achieve angiogenic synergism between the two growth factors (Ye et al. 2007). We developed a bicistronic adenoviral vector which encoded for human $\operatorname{Vegf}_{165}$ and angiopoietin-1 driven by the same promoter. The vector was used to genetically modify human skeletal myoblasts which were later transplanted in a porcine heart model of coronary artery ligation. We observed excellent survival of the transplanted skeletal myoblasts for up to 12 weeks using transient immunosuppression. Immunohistological studies showed myogenic differentiation of the skeletal myoblasts and increased blood vessel density in the infarct as well as peri-infarct regions with highest maturation index in the animal heart treated with skeletal myoblasts co-expressing Vegf and angiopoietin-1. Regional blood flow, measured with fluorescent microspheres, was significantly improved which revealed the functional competence of the newly formed blood vessels. These findings signified the feasibility of multimodal therapeutic approach based on simultaneous delivery of angiopoietin-1 and Vegf combined with cell transplantation.

Although skeletal myoblasts showed excellent ability as transgene carriers, one of the major drawbacks is their failure to develop gap junctions with the host cardiomyocytes and arrhythmogenicity (Fouts et al. 2006). We therefore hypothesized that the use of bone marrow derived mesenchymal stem cells might be a better option. Mesenchymal stem cells have been extensively studied for their cardiac reparability and regenerative potential (Chen et al. 2010; Kim et al 2010.; Labovsky et al. 2010; Haider et al. 2009) besides having superior transgene carrying capability (Chen et al. 2010; Huang et al. 2010; Tang et al. 2010; Haider et 
al. 2008). Besides, we also opted to replace Vegf with survival signaling molecule Akt to support survival of the genetically modified mesenchymal stem cells (Jiang et al. 2006). Our choice of transgene combination of angiopoietin- 1 and Akt achieved maximum beneficial effects in terms of donor stem cell survival and angiomyogenic repair of the infarcted heart. More importantly, the therapeutic benefits in terms of cell graft survival, stability of newly formed blood vessels and global cardiac function were stable for up to 3 months (Shujia et al. 2008). A more recent study has used sendai viral vector for transduction of mesenchymal stem cells, however, it remains difficult to see the advantages of mesenchymal stem cells modified with sendai vector harboring human angiopoietin-1 gene (Piao, Wang et al.)

\section{Conclusions}

Genetic modification increases the therapeutic efficacy of stem cells by improving their survival, enhancement of paracrine activity and by supporting their angiomyogenic differentiation (Tang et al. 2004). A combined cell and gene therapy approach reverses the deteriorating function of the infarcted heart (Mangi et al. 2003; Matsumoto et al. 2005) and offers an extended and localized expression of the transgene product. From the clinical standpoint, the strength of stem cell therapy and gene therapy approaches lies in their combined application to achieve stable therapeutic benefits. The viability and persistence of the genetically modified stem cells and their derivative graft in the heart can be significantly enhanced by restoration of regional blood flow via biological bypass surgery which is achieved by neovascularization of the infarcted heart. The new emerging pro-angiogenic role of angiopoietin-1 independent of VEGF, in addition to its well recognized participation in the angiogenic cascade as a maturation factor, makes angiopoietin- 1 as a growth factor of choice for ex-vivo stem cell based gene therapy which can be used independently or in combination with VEGF to support angiomyogenic recovery of the infarcted heart.

\section{Acknowledgements}

This work was supported by National Institutes of Health Grants \#R37-HL074272;HL080686;HL-087246(M.A) and HL-087288;HL-089535; HL106190-01 (Kh.H.H).

\section{References}

Abdel-Malak NA, Mofarrahi M, Mayaki D, Khachigian LM, Hussain SN. (2009). Early growth response-1 regulates angiopoietin-1-induced endothelial cell proliferation, migration, and differentiation. Arterioscler Thromb Vasc Biol 29(2): 209-16.

Abdel-Malak NA, Srikant CB, Kristof AS, Magder SA, Di Battista JA, Hussain SN. (2008). Angiopoietin-1 promotes endothelial cell proliferation and migration through AP1-dependent autocrine production of interleukin-8. Blood 111(8): 4145-54.

Ahmad S, Cudmore MJ, Wang K, Hewett P, Potluri R, Fujisawa T, Ahmed A. (2010). Angiopoietin-1 induces migration of monocytes in a tie-2 and integrin-independent manner. Hypertension 56(3): 477-83.

Armulik A, Abramsson A, Betsholtz C. (2005). Endothelial/pericyte interactions. Circ Res 97(6): 512-23.

Arsic N, Zacchigna S, Zentilin L, Ramirez-Correa G, Pattarini L, Salvi A, Sinagra G, Giacca M. (2004). Vascular endothelial growth factor stimulates skeletal muscle regeneration in vivo. Mol Ther 10(5): 844-54. 
Asahara T, Masuda H, Takahashi T, Kalka C, Pastore C, Silver M, Kearne M, Magner M, Isner JM. (1999). Bone marrow origin of endothelial progenitor cells responsible for postnatal vasculogenesis in physiological and pathological neovascularization. Circ Res 85(3): 221-8.

Babaei S, Teichert-Kuliszewska K, Zhang Q, Jones N, Dumont DJ, Stewart DJ. (2003). Angiogenic actions of angiopoietin-1 require endothelium-derived nitric oxide. Am J Pathol 162(6): 1927-36.

Bai Y, Cui M, Meng Z, Shen L, He Q, Zhang X, Chen F, Xiao J. (2009). Ectopic expression of angiopoietin-1 promotes neuronal differentiation in neural progenitor cells through the Akt pathway. Biochem Biophys Res Commun 378(2): 296-301.

Bai Y, Meng Z, Cui M, Zhang X, Chen F, Xiao J, Shen L, Zhang Y. (2009). An Ang1-Tie2-PI3K axis in neural progenitor cells initiates survival responses against oxygen and glucose deprivation. Neuroscience 160(2): 371-81.

Banai S, Jaklitsch MT, Shou M, Lazarous DF, Scheinowitz M, Biro S, Epstein SE, Unger EF. (1994). Angiogenic-induced enhancement of collateral blood flow to ischemic myocardium by VEGF in dogs. Circulation 89(5): 2183-9.

Bentley K, Mariggi G, Gerhardt H, Bates PA. (2009). Tipping the balance: robustness of tip cell selection, migration and fusion in angiogenesis. PLoS Comput Biol 5(10): e1000549.

Brindle NP, Saharinen P, Alitalo K. (2006). Signaling and functions of angiopoietin-1 in vascular protection. Circ Res 98(8): 1014-23.

Carmeliet, P. (2000). Mechanisms of angiogenesis and arteriogenesis. Nat Med 6(4): 389-95.

Chen Y, Liu W, Li W, Gao C. (2010). Autologous bone marrow mesenchymal cell transplantation improves left ventricular function in a rabbit model of dilated cardiomyopathy. Exp Mol Pathol 88(2): 311-5.

Cheng M, Park H, Engelmayr GC, Moretti M, Freed LE. (2007). Effects of regulatory factors on engineered cardiac tissue in vitro. Tissue Eng 13(11): 2709-19.

Chiu LL, \& Radisic M. Scaffolds with covalently immobilized VEGF and Angiopoietin-1 for vascularization of engineered tissues. Biomaterials 31(2): 226-41.

Davis S, Papadopoulos N, Aldrich TH, Maisonpierre PC, Huang T, Kovac L, Xu A, Leidich R, Radziejewska E, Rafique A, Goldberg J, Jain V, Bailey K, Karow M, Fandl J, Samuelsson SJ, Ioffe E, Rudge JS, Daly TJ, Radziejewski C, Yancopoulos GD. (2004). Angiopoietin-1 modulates endothelial cell function and gene expression via the transcription factor FKHR (FOXO1). Genes Dev 18(9): 1060-71.

Davis S, Aldrich TH, Jones PF, Acheson A, Compton DL, Jain V, Ryan TE, Bruno J, Radziejewski C, Maisonpierre PC, Yancopoulos GD. (1996). Isolation of angiopoietin-1, a ligand for the TIE2 receptor, by secretion-trap expression cloning. Cell 87(7): 1161-9.

Davis, S., N. Papadopoulos, et al. (2003). Angiopoietins have distinct modular domains essential for receptor binding, dimerization and superclustering. Nat Struct Biol 10(1): 38-44.

Dumont DJ, Gradwohl G, Fong GH, Puri MC, Gertsenstein M, Auerbach A, Breitman ML. (1994). "Dominant-negative and targeted null mutations in the endothelial receptor tyrosine kinase, tek, reveal a critical role in vasculogenesis of the embryo. Genes Dev 8(16): 1897-909. 
Dumont DJ, Yamaguchi TP, Conlon RA, Rossant J, Breitman ML. (1992). tek, a novel tyrosine kinase gene located on mouse chromosome 4 , is expressed in endothelial cells and their presumptive precursors. Oncogene 7(8): 1471-80.

Eguchi M, Masuda H, Asahara T. (2007). Endothelial progenitor cells for postnatal vasculogenesis. Clin Exp Nephrol 11(1): 18-25.

Elmadbouh I, Haider H, Jiang S, Idris NM, Lu G, Ashraf M. (2007). Ex vivo delivered stromal cell-derived factor-1alpha promotes stem cell homing and induces angiomyogenesis in the infarcted myocardium. J Mol Cell Cardiol 42(4): 792-803.

Evans-Anderson HJ, Alfieri CM, Yutzey KE. (2008). Regulation of cardiomyocyte proliferation and myocardial growth during development by FOXO transcription factors. Circ Res 102(6): 686-94.

Feng Y, Vom Hagen F, Wang Y, Beck S, Schreiter K, Pfister F, Hoffmann S, Wagner P, Seeliger M, Molema G, Deutsch U, Hammes HP. (2009). The absence of angiopoietin-2 leads to abnormal vascular maturation and persistent proliferative retinopathy. Thromb Haemost 102(1): 120-30.

Fiedler U, Krissl T, Koidl S, Weiss C, Koblizek T, Deutsch U, Martiny-Baron G, Marme D, Augustin HG. (2003). Angiopoietin-1 and angiopoietin-2 share the same binding domains in the Tie-2 receptor involving the first Ig-like loop and the epidermal growth factor-like repeats. J Biol Chem 278(3): 1721-7.

Fouts K, Fernandes B, Mal N, Liu J, Laurita KR. (2006). Electrophysiological consequence of skeletal myoblast transplantation in normal and infarcted canine myocardium. Heart Rhythm 3(4): 452-61.

Fujii, T. \& H. Kuwano Regulation of the expression balance of angiopoietin-1 and angiopoietin-2 by Shh and FGF-2. In Vitro Cell Dev Biol Anim 46(6): 487-91.

Fujikawa K, de Aos Scherpenseel I, Jain SK, Presman E, Christensen RA, Varticovski L. (1999). Role of PI 3-kinase in angiopoietin-1-mediated migration and attachmentdependent survival of endothelial cells. Exp Cell Res 253(2): 663-72.

Gale NW, Thurston G, Davis S, Wiegand SJ, Holash J, Rudge JS, Yancopoulos GD. (2002). Complementary and coordinated roles of the VEGFs and angiopoietins during normal and pathologic vascular formation. Cold Spring Harb Symp Quant Biol 67: 267-73.

Gomei Y, Nakamura Y, Yoshihara H, Hosokawa K, Iwasaki H, Suda T, Arai F. (2010) Functional differences between two Tie2 ligands, angiopoietin-1 and -2 , in regulation of adult bone marrow hematopoietic stem cells." Exp Hematol 38(2): 82-9.

Gratton JP, Morales-Ruiz M, Kureishi Y, Fulton D, Walsh K, Sessa WC. (2001). Akt downregulation of p38 signaling provides a novel mechanism of vascular endothelial growth factor-mediated cytoprotection in endothelial cells. J Biol Chem 276(32): 30359-65.

Gurunluoglu R, Ozer K, Skugor B, Lubiatowski P, Carnevale K, Siemionow M. (2002). Effect of transfection time on the survival of epigastric skin flaps pretreated with adenovirus encoding the VEGF gene. Ann Plast Surg 49(2): 161-9.

Haider H, Jiang S, Idris NM, Ashraf M. (2008). IGF-1-overexpressing mesenchymal stem cells accelerate bone marrow stem cell mobilization via paracrine activation of SDF1alpha/CXCR4 signaling to promote myocardial repair. Circ Res 103(11): 1300-8. 
Haider H, Ye L, Jiang S, Ge R, Law PK, Chua T, Wong P, Sim EK. Angiomyogenesis for cardiac repair using human myoblasts as carriers of human vascular endothelial growth factor. J Mol Med 82(8): 539-49.

Haider KH, Kim HW, Ashraf M. (2009). Hypoxia-inducible factor-1alpha in stem cell preconditioning: mechanistic role of hypoxia-related micro-RNAs. J Thorac Cardiovasc Surg 138(1): 257.

Hamaguchi I, Morisada T, Azuma M, Murakami K, Kuramitsu M, Mizukami T, Ohbo K, Yamaguchi K, Oike Y, Dumont DJ, Suda T. (2006). Loss of Tie2 receptor compromises embryonic stem cell-derived endothelial but not hematopoietic cell survival. Blood 107(3): 1207-13.

Hansen TM, Singh H, Tahir TA, Brindle NP. (2010). Effects of angiopoietins-1 and -2 on the receptor tyrosine kinase Tie 2 are differentially regulated at the endothelial cell surface. Cell Signal 22(3): 527-32.

Harfouche R, Gratton JP, Yancopoulos GD, Noseda M, Karsan A, Hussain SN. (2003). Angiopoietin-1 activates both anti- and proapoptotic mitogen-activated protein kinases. Faseb J 17(11): 1523-5.

Hattori K, Dias S, Heissig B, Hackett NR, Lyden D, Tateno M, Hicklin DJ, Zhu Z, Witte L, Crystal RG, Moore MA, Rafii S. (2001). Vascular endothelial growth factor and angiopoietin-1 stimulate postnatal hematopoiesis by recruitment of vasculogenic and hematopoietic stem cells. J Exp Med 193(9): 1005-14.

Hayes AJ, Huang WQ, Mallah J, Yang D, Lippman ME, Li LY. (1999). Angiopoietin-1 and its receptor Tie-2 participate in the regulation of capillary-like tubule formation and survival of endothelial cells. Microvasc Res 58(3): 224-37.

Hiasa K, Ishibashi M, Ohtani K, Inoue S, Zhao Q, Kitamoto S, Sata M, Ichiki T, Takeshita A, Egashira K. (2004). Gene transfer of stromal cell-derived factor-1alpha enhances ischemic vasculogenesis and angiogenesis via vascular endothelial growth factor/endothelial nitric oxide synthase-related pathway: next-generation chemokine therapy for therapeutic neovascularization. Circulation 109(20): 2454-61.

Huang H, \& Tindall DJ. (2007). Dynamic FoxO transcription factors. J Cell Sci 120(Pt 15): 2479-87.

Huang J, Bae JO, Tsai JP, Kadenhe-Chiweshe A, Papa J, Lee A, Zeng S, Kornfeld ZN, Ullner P, Zaghloul N, Ioffe E, Nandor S, Burova E, Holash J, Thurston G, Rudge J, Yancopoulos GD, Yamashiro DJ, Kandel JJ. (2009). Angiopoietin-1/Tie-2 activation contributes to vascular survival and tumor growth during VEGF blockade. Int $J$ Oncol 34(1): 79-87.

Huang J, Zhang Z, Guo J, Ni A, Deb A, Zhang L, Mirotsou M, Pratt RE, Dzau VJ. (2010) Genetic modification of mesenchymal stem cells overexpressing CCR1 increases cell viability, migration, engraftment, and capillary density in the injured myocardium. Circ Res 106(11): 1753-62.

Hughes DP, Marron MB, Brindle NP. (2003). The antiinflammatory endothelial tyrosine kinase Tie2 interacts with a novel nuclear factor-kappaB inhibitor ABIN-2. Circ Res 92(6): 630-6.

Jeon BH, Khanday F, Deshpande S, Haile A, Ozaki M, Irani K. (2003). Tie-ing the antiinflammatory effect of angiopoietin-1 to inhibition of NF-kappaB. Circ Res 92(6): 586-8. 
Jiang S, Haider H, Idris NM, Salim A, Ashraf M. (2006). Supportive interaction between cell survival signaling and angiocompetent factors enhances donor cell survival and promotes angiomyogenesis for cardiac repair. Circ Res 99(7): 776-84.

Kalka C, Masuda H, Takahashi T, Gordon R, Tepper O, Gravereaux E, Pieczek A, Iwaguro H, Hayashi SI, Isner JM, Asahara T. (2000). Vascular endothelial growth factor(165) gene transfer augments circulating endothelial progenitor cells in human subjects. Circ Res 86(12): 1198-202.

Kanda S, Miyata Y, Mochizuki Y, Matsuyama T, Kanetake H. (2005). Angiopoietin 1 is mitogenic for cultured endothelial cells. Cancer Res 65(15): 6820-7.

Kim HW, Haider HK, Jiang S, Ashraf M. (2009). Ischemic preconditioning augments survival of stem cells via miR-210 expression by targeting caspase-8-associated protein 2. J Biol Chem 284(48): 33161-8.

Kim I, Oh JL, Ryu YS, So JN, Sessa WC, Walsh K, Koh GY. (2002). Angiopoietin-1 negatively regulates expression and activity of tissue factor in endothelial cells. Faseb J 16(1): 126-8.

Kim I, Ryu YS, Kwak HJ, Ahn SY, Oh JL, Yancopoulos GD, Gale NW, Koh GY. (2002). EphB ligand, ephrinB2, suppresses the VEGF- and angiopoietin 1-induced Ras/mitogenactivated protein kinase pathway in venous endothelial cells. Faseb J 16(9): 1126-8.

Kim KT, Choi HH, Steinmetz MO, Maco B, Kammerer RA, Ahn SY, Kim HZ, Lee GM, Koh GY. (2005). Oligomerization and multimerization are critical for angiopoietin-1 to bind and phosphorylate Tie2. J Biol Chem 280(20): 20126-31.

Kim SK, Pak HN, Park JH, Fang YF, Kim GI, Park YD, Hwang C, Kim YH, Kim BS. Cardiac cell therapy with mesenchymal stem cell induces cardiac nerve sprouting, angiogenesis, and reduced connexin43-positive gap junctions, but concomitant electrical pacing increases connexin43-positive gap junctions in canine heart. Cardiol Young 20(3): 308-17.

Koblizek TI, Weiss C, Yancopoulos GD, Deutsch U, Risau W. (1998). Angiopoietin-1 induces sprouting angiogenesis in vitro. Curr Biol 8(9): 529-32.

Kosacka J, Figiel M, Engele J, Hilbig H, Majewski M, Spanel-Borowski K. (2005). Angiopoietin-1 promotes neurite outgrowth from dorsal root ganglion cells positive for Tie-2 receptor. Cell Tissue Res 320(1): 11-9.

Labovsky V, Hofer EL, Feldman L, Fernandez Vallone V, Garcia Rivello H, Bayes-Genis A, Hernando Insua A, Levin MJ, Chasseing NA. (2010). Cardiomyogenic differentiation of human bone marrow mesenchymal cells: Role of cardiac extract from neonatal rat cardiomyocytes. Differentiation 79(2): 93-101.

Lee S, Kim W, Kim DH, Moon SO, Jung YJ, Lee AS, Kang KP, Jang KY, Lee SY, Sung MJ, Koh GY, Park SK. (2008). Protective effect of COMP-angiopoietin-1 on cyclosporine-induced renal injury in mice. Nephrol Dial Transplant 23(9): 2784-94.

Liu XB, Jiang J, Gui C, Hu XY, Xiang MX, Wang JA. (2008). Angiopoietin-1 protects mesenchymal stem cells against serum deprivation and hypoxia-induced apoptosis through the PI3K/Akt pathway. Acta Pharmacol Sin 29(7): 815-22.

Lu G, Haider HK, Jiang S, Ashraf M. (2009). Sca-1+ stem cell survival and engraftment in the infarcted heart: dual role for preconditioning-induced connexin-43. Circulation 119(19): 2587-96. 
Lyons MS, Bell B, Stainier D, Peters KG. (1998). Isolation of zebrafish homologues for the tie1 and tie-2 endothelium-specific receptor tyrosine kinases. Dev Dyn 212(1): 133-40.

Maisonpierre PC, Suri C, Jones PF, Bartunkova S, Wiegand SJ, Radziejewski C, Compton D, McClain J, Aldrich TH, Papadopoulos N, Daly TJ, Davis S, Sato TN, Yancopoulos GD. (1997). Angiopoietin-2, a natural antagonist for Tie2 that disrupts in vivo angiogenesis. Science 277(5322): 55-60.

Mangi AA, Noiseux N, Kong D, He H, Rezvani M, Ingwall JS, Dzau VJ. (2003). Mesenchymal stem cells modified with Akt prevent remodeling and restore performance of infarcted hearts. Nat Med 9(9): 1195-201.

Matsumoto R, Omura T, Yoshiyama M, Hayashi T, Inamoto S, Koh KR, Ohta K, Izumi Y, Nakamura Y, Akioka K, Kitaura Y, Takeuchi K, Yoshikawa J. (2005). Vascular endothelial growth factor-expressing MSC transplantation for the treatment of acute myocardial infarction. Arterioscler Thromb Vasc Biol 25(6): 1168-73.

McCarter SD, Lai PF, Suen RS, Stewart DJ. (2006). Regulation of endothelin-1 by Ang-1: implications for inflammation. Exp Biol Med (Maywood) 231(6): 985-91.

Morris PN, Dunmore BJ, Tadros A, Marchuk DA, Darland DC, D'Amore PA, Brindle NP. (2005). Functional analysis of a mutant form of the receptor tyrosine kinase Tie2 causing venous malformations. J Mol Med 83(1): 58-63.

Murray BW, Padrique ES, Pinko C, McTigue MA. (2001). Mechanistic effects of autophosphorylation on receptor tyrosine kinase catalysis: enzymatic characterization of Tie2 and phospho-Tie2. Biochemistry 40(34): 10243-53.

Nakayama T, Hatachi G, Wen CY, Yoshizaki A, Yamazumi K, Niino D, Sekine I. (2005). Expression and significance of Tie-1 and Tie-2 receptors, and angiopoietins-1, 2 and 4 in colorectal adenocarcinoma: Immunohistochemical analysis and correlation with clinicopathological factors. World J Gastroenterol 11(7): 964-9.

Niagara MI, Haider H, Ye L, Koh VS, Lim YT, Poh KK, Ge R, Sim EK. (2004). Autologous skeletal myoblasts transduced with a new adenoviral bicistronic vector for treatment of hind limb ischemia. J Vasc Surg 40(4): 774-85.

Piao W, Wang H, Inoue M, Hasegawa M, Hamada H, Huang J. (2010). Transplantation of sendai viral angiopoietin-1-modified mesenchymal stem cells for ischemic limb disease." Angiogenesis 13(3): 203-10.

Saharinen P, Kerkela K, Ekman N, Marron M, Brindle N, Lee GM, Augustin H, Koh GY, Alitalo K. (2005). Multiple angiopoietin recombinant proteins activate Tie1 receptor tyrosine kinase and promote its interaction with Tie2.J Cell Biol 169(2): 239-43.

Samuel SM, Akita Y, Paul D, Thirunavukkarasu M, Zhan L, Sudhakaran PR, Li C, Maulik N. Coadministration of adenoviral vascular endothelial growth factor and angiopoietin-1 enhances vascularization and reduces ventricular remodeling in the infarcted myocardium of type 1 diabetic rats. Diabetes 59(1): 51-60.

Sato TN, Tozawa Y, Deutsch U, Wolburg-Buchholz K, Fujiwara Y, Gendron-Maguire M, Gridley T, Wolburg H, Risau W, Qin Y. (1995). Distinct roles of the receptor tyrosine kinases Tie-1 and Tie-2 in blood vessel formation. Nature 376(6535): 70-4.

Seegar TC, Eller B, Tzvetkova-Robev D, Kolev MV, Henderson SC, Nikolov DB, Barton WA. (2010). Tie1-Tie2 interactions mediate functional differences between angiopoietin ligands. Mol Cell 37(5): 643-55. 
Shujia J, Haider HK, Idris NM, Lu G, Ashraf M. (2008). Stable therapeutic effects of mesenchymal stem cell-based multiple gene delivery for cardiac repair. Cardiovasc Res 77(3): 525-33.

Shyu KG, Chang H, Isner JM. (2003). Synergistic effect of angiopoietin-1 and vascular endothelial growth factor on neoangiogenesis in hypercholesterolemic rabbit model with acute hindlimb ischemia. Life Sci 73(5): 563-79.

Siddiqui AJ, Blomberg P, Wardell E, Hellgren I, Eskandarpour M, Islam KB, Sylven C. (2003). Combination of Ang-1 and VEGF gene therapy enhances arteriogenesis in the ischemic myocardium. Biochem Biophys Res Commun 310(3): 1002-9.

Song H, Suehiro J, Kanki Y, Kawai Y, Inoue K, Daida H, Yano K, Ohhashi T, Oettgen P, Aird WC, Kodama T, Minami T. (2009). Critical role for GATA3 in mediating Tie2 expression and function in large vessel endothelial cells. J Biol Chem 284(42): 2910924.

Sundberg C, Kowanetz M, Brown LF, Detmar M, Dvorak HF. (2002). Stable expression of angiopoietin-1 and other markers by cultured pericytes: phenotypic similarities to a subpopulation of cells in maturing vessels during later stages of angiogenesis in vivo. Lab Invest 82(4): 387-401.

Suri C, Jones PF, Patan S, Bartunkova S, Maisonpierre PC, Davis S, Sato TN, Yancopoulos GD. (1996). Requisite role of angiopoietin-1, a ligand for the TIE2 receptor, during embryonic angiogenesis. Cell 87(7): 1171-80.

Suri C, McClain J, Thurston G, McDonald DM, Zhou H, Oldmixon EH, Sato TN, Yancopoulos GD. (1998). Increased vascularization in mice overexpressing angiopoietin-1. Science 282(5388): 468-71.

Suzuki K, Murtuza B, Smolenski RT, Sammut IA, Suzuki N, Kaneda Y, Yacoub MH. (2001). Cell transplantation for the treatment of acute myocardial infarction using vascular endothelial growth factor-expressing skeletal myoblasts. Circulation 104(12 Suppl 1): I207-12.

Takahara K, lioka T, Furukawa K, Uchida T, Nakashima M, Tsukazaki T, Shindo H. (2004). Autocrine/paracrine role of the angiopoietin-1 and -2/Tie2 system in cell proliferation and chemotaxis of cultured fibroblastic synoviocytes in rheumatoid arthritis. Hum Pathol 35(2): 150-8.

Tang J, Wang J, Guo L, Kong X, Yang J, Zheng F, Zhang L, Huang Y. (2010). Mesenchymal stem cells modified with stromal cell-derived factor 1 alpha improve cardiac remodeling via paracrine activation of hepatocyte growth factor in a rat model of myocardial infarction." Mol Cells 29(1): 9-19.

Tang YL, Zhao Q, Zhang YC, Cheng L, Liu M, Shi J, Yang YZ, Pan C, Ge J, Phillips MI. (2004). Autologous mesenchymal stem cell transplantation induce VEGF and neovascularization in ischemic myocardium. Regul Pept 117(1): 3-10.

Tao Z, Chen B, Tan X, Zhao Y, Wang L, Zhu T, Cao K, Yang Z, Kan YW, Su H. Coexpression of VEGF and angiopoietin-1 promotes angiogenesis and cardiomyocyte proliferation reduces apoptosis in porcine myocardial infarction (MI) heart. Proc Natl Acad Sci U S A 108(5): 2064-9.

Thomas M, Augustin HG. (2009). The role of the Angiopoietins in vascular morphogenesis. Angiogenesis 12(2): 125-37. 
Thurston, G. (2002). "Complementary actions of VEGF and angiopoietin-1 on blood vessel growth and leakage. J Anat 200(6): 575-80.

Thurston G, Rudge JS, Ioffe E, Zhou H, Ross L, Croll SD, Glazer N, Holash J, McDonald DM, Yancopoulos GD. (2000). Angiopoietin-1 protects the adult vasculature against plasma leakage. Nat Med 6(4): 460-3.

Thurston G, Suri C, Smith K, McClain J, Sato TN, Yancopoulos GD, McDonald DM. (1999). Leakage-resistant blood vessels in mice transgenically overexpressing angiopoietin1. Science 286(5449): 2511-4.

Tuo QH, Xiong GZ, Zeng H, Yu HD, Sun SW, Ling HY, Zhu BY, Liao DF, Chen JX. (2010). Angiopoietin-1 protects myocardial endothelial cell function blunted by angiopoietin-2 and high glucose condition. Acta Pharmacol Sin 32(1): 45-51.

Uemura R, Xu M, Ahmad N, Ashraf M. (2006). BM stem cells prevent left ventricular remodeling of ischemic heart through paracrine signaling." Circ Res 98(11): 1414-21.

Valenzuela DM, Griffiths JA, Rojas J, Aldrich TH, Jones PF, Zhou H, McClain J, Copeland NG, Gilbert DJ, Jenkins NA, Huang T, Papadopoulos N, Maisonpierre PC, Davis S, Yancopoulos GD. (1999). Angiopoietins 3 and 4: diverging gene counterparts in mice and humans. Proc Natl Acad Sci U S A 96(5): 1904-9.

Voskas D, Jones N, Van Slyke P, Sturk C, Chang W, Haninec A, Babichev YO, Tran J, Master Z, Chen S, Ward N, Cruz M, Jones J, Kerbel RS, Jothy S, Dagnino L, Arbiser J, Klement G, Dumont DJ. (2005). A cyclosporine-sensitive psoriasis-like disease produced in Tie2 transgenic mice. Am J Pathol 166(3): 843-55.

Wang H, Zhang Y, Toratani S, Okamoto T. (2004). Transformation of vascular endothelial cells by a point mutation in the Tie2 gene from human intramuscular haemangioma. Oncogene 23(53): 8700-4.

Wang Y, Haider HK, Ahmad N, Xu M, Ge R, Ashraf M. (2006). Combining pharmacological mobilization with intramyocardial delivery of bone marrow cells over-expressing VEGF is more effective for cardiac repair. J Mol Cell Cardiol 40(5): 736-45.

Witzenbichler B, Maisonpierre PC, Jones P, Yancopoulos GD, Isner JM. (1998). Chemotactic properties of angiopoietin-1 and -2, ligands for the endothelial-specific receptor tyrosine kinase Tie2. J Biol Chem 273(29): 18514-21.

Yau TM, Kim C, Li G, Zhang Y, Fazel S, Weisel RD, Li RK. (2007). Enhanced angiogenesis with multimodal cell-based gene therapy. Ann Thorac Surg 83(3): 1110-9.

Ye L, Haider H, Jiang S, Tan RS, Ge R, Law PK, Sim EK. (2007). Improved angiogenic response in pig heart following ischaemic injury using human skeletal myoblast simultaneously expressing VEGF165 and angiopoietin-1. Eur J Heart Fail 9(1): 15-22.

Ye L, Haider H, Jiang S, Tan RS, Toh WC, Ge R, Sim EK. (2007). Angiopoietin-1 for myocardial angiogenesis: a comparison between delivery strategies. Eur J Heart Fail 9(5): 458-65.

Ye L, Haider H, Tan R, Toh W, Law PK, Tan W, Su L, Zhang W, Ge R, Zhang Y, Lim Y, Sim EK. (2007). Transplantation of nanoparticle transfected skeletal myoblasts overexpressing vascular endothelial growth factor-165 for cardiac repair. Circulation 116(11 Suppl): I113-20.

Yu Y, Varughese J, Brown LF, Mulliken JB, Bischoff J. (2001). Increased Tie2 expression, enhanced response to angiopoietin-1, and dysregulated angiopoietin-2 expression in hemangioma-derived endothelial cells. Am J Pathol 159(6): 2271-80. 
Zhu WH, Han J, Nicosia RF. (2003). Requisite role of p38 MAPK in mural cell recruitment during angiogenesis in the rat aorta model. J Vasc Res 40(2): 140-8.

Zhu WH, MacIntyre A, Nicosia RF. (2002). Regulation of angiogenesis by vascular endothelial growth factor and angiopoietin-1 in the rat aorta model: distinct temporal patterns of intracellular signaling correlate with induction of angiogenic sprouting. Am J Pathol 161(3): 823-30. 


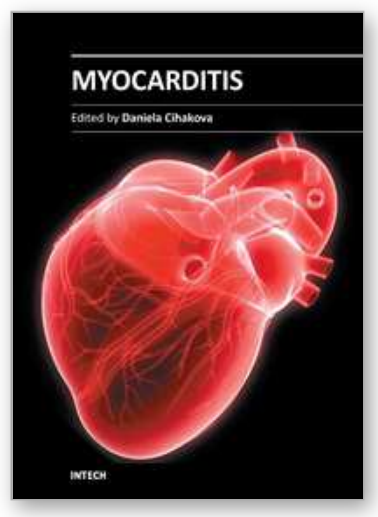

\author{
Myocarditis \\ Edited by Dr. Daniela Cihakova
}

ISBN 978-953-307-289-0

Hard cover, 428 pages

Publisher InTech

Published online 19, October, 2011

Published in print edition October, 2011

Myocarditis, the inflammation of the heart muscle, could be in some cases serious and potentially fatal disease. This book is a comprehensive compilation of studies from leading international experts on various aspects of myocarditis. The first section of the book provides a clinical perspective on the disease. It contains comprehensive reviews of the causes of myocarditis, its classification, diagnosis, and treatment. It also includes reviews of Perimyocarditis; Chagasâ $€^{\mathrm{TM}}$ chronic myocarditis, and myocarditis in HIV-positive patients. The second section of the book focuses on the pathogenesis of myocarditis, discussing pathways and mechanisms activated during viral infection and host immune response during myocarditis. The third, and final, section discusses new findings in the pathogenesis that may lead to new directions for clinical diagnosis, including use of new biomarkers, and new treatments of myocarditis.

\title{
How to reference
}

In order to correctly reference this scholarly work, feel free to copy and paste the following:

Vien Khach Lai, Muhammad Zeeshan Afzal, Muhammad Ashraf and Khawaja Husnain Haider (2011). Angiopoietin-1 for Myocardial Angiogenesis, Myocarditis, Dr. Daniela Cihakova (Ed.), ISBN: 978-953-307-2890, InTech, Available from: http://www.intechopen.com/books/myocarditis/angiopoietin-1-for-myocardialangiogenesis

\section{INTECH}

open science | open minds

\author{
InTech Europe \\ University Campus STeP Ri \\ Slavka Krautzeka 83/A \\ 51000 Rijeka, Croatia \\ Phone: +385 (51) 770447 \\ Fax: +385 (51) 686166 \\ www.intechopen.com
}

\author{
InTech China \\ Unit 405, Office Block, Hotel Equatorial Shanghai \\ No.65, Yan An Road (West), Shanghai, 200040, China \\ 中国上海市延安西路65号上海国际贵都大饭店办公楼 405 单元 \\ Phone: +86-21-62489820 \\ Fax: +86-21-62489821
}


(C) 2011 The Author(s). Licensee IntechOpen. This is an open access article distributed under the terms of the Creative Commons Attribution 3.0 License, which permits unrestricted use, distribution, and reproduction in any medium, provided the original work is properly cited. 